\title{
Conforto térmico animal e humano em galpões de frangos de corte no semiárido mineiro
}

\author{
Cinara da C. S. Carvalho ${ }^{1}$, Tatiany C. dos Santos ${ }^{2}$, Geruza C. da Silva ${ }^{3}$, \\ Laize V. Santos ${ }^{4}$, Sóstenes de J. M. Moreira ${ }^{5} \&$ Luiz F. R. Botelho ${ }^{6}$
}

\author{
1 UNIMONTES. Janaúba, MG. E-mail: cinara.carvalho@unimontes.br (Autora correspondente) \\ ${ }^{2}$ UNIMONTES. Janaúba, MG. E-mail: taty17_carvalho@hotmail.com \\ ${ }^{3}$ UNIMONTES. Janaúba, MG. E-mail: geruzacardoso@hotmail.com \\ ${ }^{4}$ UNIMONTES. Janaúba, MG. E-mail: santos.laize@yahoo.com.br \\ ${ }^{5}$ UNIMONTES. Janaúba, MG. E-mail: moreirasostenes@bol.com.br \\ ${ }^{6}$ UNIMONTES. Janaúba, MG. E-mail: luiz.fernando1989@zootecnista.com.br
}

\section{Palavras-chave:}

avicultura

ambiente térmico

ergonomia

\begin{abstract}
R E S U M O
Com base na importância que o tema bem-estar tem atingido atualmente buscou-se, com este trabalho, avaliar a condição de conforto térmico para os animais e trabalhadores, durante os primeiros 21 dias de vida de pintos de corte criados em galpões na região do semiárido Mineiro, local onde a temperatura média anual é em torno de $27^{\circ} \mathrm{C}$. $\mathrm{O}$ trabalho foi desenvolvido em duas fases distintas (inverno e verão) em uma granja avícola localizada na cidade de Nova Porteirinha (MG). Para avaliar o conforto térmico dos animais utilizou-se o Índice de Temperatura de Globo Negro e Umidade (ITGU) e, para caracterizar o ambiente térmico para os trabalhadores, adotou-se o Índice de Bulbo Úmido e Termômetro de Globo Negro (IBUTG). De posse dos dados coletados observou-se que, independente da estação do ano, os valores de ITGU estiveram acima de 74 caracterizando condição de estresse térmico para os pintos de corte. Com relação aos trabalhadores verificou-se que a atividade de manejo da granja realizada durante o inverno, não expõe as pessoas à condição de sobrecarga térmica; entretanto, no verão os funcionários precisam, a partir das 09:00 h, adotar pausas frequentes para reestabelecimento fisiológico, com hidratação e descanso.
\end{abstract}

Key words: poultry production thermal environment ergonomics

\section{Animal and human thermal comfort in poultry houses in Brazilian semiarid}

\begin{abstract}
A B S T R A C T
Given the importance that the issue wellbeing has reached today, the aim of this study was to evaluate the condition of thermal comfort for the animals and workers during the first 21 days of life of poultry reared in sheds in the region of semiarid Minas Gerais state, where the mean annual temperature is around $27^{\circ} \mathrm{C}$. The study was conducted in two distinct phases (winter and summer) at a poultry farm in the Nova Porteirinha city (MG). To evaluate the thermal comfort of the animals, the index of Black Globe Temperature and Humidity (BGHI) was used and to characterize the thermal environment for workers, the Index of Wet Bulb Globe Temperature (WBGT) and was adopted. The data collected revealed that regardless of season, the values were above 74 WBGT featuring heat stress condition for broiler chicks. With regard to workers, it was found that the activity of farm management conducted during the winter does not expose people to thermal overload condition, however, in the summer, from 9 am, employees need to take frequent breaks to reestablish physiologically with hydration and rest.
\end{abstract}

\section{INTRODUÇão}

O sistema produtivo avícola brasileiro tem investido, de forma incansável, em ferramentas que possam otimizar a produção de carne de frangos. Frente às atuais demandas existentes verifica-se uma intensa busca por conhecimento e técnicas que visam favorecer a máxima produtividade de carne com o menor custo (Ponciano et al., 2011).

A avicultura brasileira é avançada em genética, nutrição e sanidade; no entanto, as grandes variações climáticas existentes no território associadas, algumas vezes, a instalações que não favorecem a ventilação e a renovação do ar adequada, podem vir a comprometer a produtividade (Tinôco, 2001).

Neste sentido sabe-se que a produção de frangos de corte é alcançada quando os mesmos são criados em ambiente termicamente adequado onde não há necessidade para que os mesmos despendam energia, para compensar o frio ou o calor.

O controle do ambiente térmico no interior das instalações nas quais os animais estão alojados deve ser maior durante as primeiras semanas de vida das aves e com maior rigor durante o período de inverno (Menegali et al., 2010). 
A exposição a baixas temperaturas compromete a formação do sistema termorregulatório ocasionando o desenvolvimento de doenças dos sistemas respiratório, prejudicando o desenvolvimento e a produtividade das aves principalmente durante o período inicial de vida dos pintinhos (Cordeiro et al., 2011).

Embora as condições climáticas no Norte de Minas Gerais sejam, teoricamente, favoráveis para a criação de frangos de corte durante a fase inicial, existe uma preocupação por parte dos criadores de vez que as temperaturas são elevadas e a faixa de conforto térmico pode, então, ser extrapolada para a zona de hipertermia.

Condições térmicas fora da zona de conforto são premissas também para o desenvolvimento de problemas de saúde nos trabalhadores, que executam atividades que demandam atenção e agilidade e podem ser prejudicadas devido à falta de concentração e fadiga decorrentes do calor (Carvalho et al., 2011, Damasceno et al., 2010).

As atividades de manejo desenvolvidas em granjas de frangos de corte são associadas, em geral, a um manejo intenso com sobrecarga de peso; a exemplo disto tem-se o revolvimento de cama e o preenchimento de comedouro de forma manual. Essas atividades exigem muito esforço dos trabalhadores e precisam ser desenvolvidas em tempo hábil; no entanto, quando o ambiente é desconfortável termicamente, seja por frio ou por calor, o ritmo de realização dessas atividades e sua qualidade, fica prejudicado (Carvalho et al., 2011).

Sendo assim objetivou-se, neste trabalho, avaliar a condição de conforto térmico para os pintos de corte, durante os primeiros 21 dias de vidas, tal como a condição de conforto para as pessoas que trabalham nesses galpões no período de inverno e verão, na região Norte de Minas Gerais.

\section{Material e Métodos}

O trabalho foi desenvolvido em granja avícola, responsável pela produção de frangos de corte na região Norte de Minas Gerais, localizada na cidade de Nova Porteirinha (MG). O município se encontra na latitude de $15^{\circ} 47^{\prime} 50^{\prime \prime} \mathrm{S}$, longitude $43^{\circ}$ $18^{\prime} 31^{\prime \prime} \mathrm{W}$, altitude de $516 \mathrm{~m}$ e clima, segundo Köppen, do tipo AW (tropical chuvoso, savana com inverno seco).

Os dados foram coletados durante o inverno de 2011, no período de 7 a 28 de julho e durante o verão, no período de 5 a 27 de janeiro de 2012 compreendendo, desta forma, 21 dias iniciais de vida dos animais. Nesta fase os pintinhos eram aquecidos por meio do uso de uma fornalha tipo asa de morcego, abastecida a lenha e posicionada no centro da área de pinteiro.

O aviário em que o experimento foi realizado está orientado no sentido Leste-Oeste, com dimensões de $23 \mathrm{~m}$ de comprimento, $6,30 \mathrm{~m}$ de largura e pé-direito de $3 \mathrm{~m}$. A instalação foi equipada com 30 comedouros tubulares e 30 bebedouros pendulares.

Durante o período experimental foram realizadas medições diárias das variáveis ambientais por meio do uso de dois dataloggers da marca EXTECH, modelo RHT 10, com resolução de $\pm 1{ }^{\circ} \mathrm{C}, \pm 3,5 \%$ (umidade) e $\pm 2^{\circ}$ para temperatura do ponto de orvalho.
Os equipamentos foram programados para registrar os dados a cada $15 \mathrm{~min}$, com início às $8 \mathrm{~h}$ e término às $17 \mathrm{~h}$ e instalados no centro do galpão posicionados a uma altura de 0,30 e 1,70 m do piso, medida relativa à altura das aves e dos trabalhadores, respectivamente. De posse dos dados registrados calculou-se inicialmente o ITGU por meio da fórmula desenvolvida por Buffington et al. (1981).

$$
\mathrm{ITGU}=\mathrm{Tgn}+0,36 \mathrm{Tpo}+41,5
$$

em que:

ITGU - índice de temperatura de globo negro e umidade

Tgn - temperatura de globo negro, ${ }^{\circ} \mathrm{C}$

Tpo - temperatura do ponto de orvalho, ${ }^{\circ} \mathrm{C}$

Os ITGUs obtidos foram confrontados com os valores sugeridos por Menegali et al. (2010) cuja faixa de 74 a 77 caracteriza condição de conforto, valores abaixo de 74 estresse por frio e acima de 77 condição perigosa devido ao estresse por calor.

Para caracterizar a condição de conforto térmico para humanos utilizou-se o IBUTG que foi calculado por meio da equação descrita a seguir, adequado para avaliação de ambientes internos (sem carga solar) de acordo com o estabelecido pela NR 15 (2004):

$$
\text { IBUTG }=0,7 \text { Tbn }+0,3 \text { Tgn }
$$

em que:

Tbn - temperatura de bulbo úmido natural, ${ }^{\circ} \mathrm{C}$

$\mathrm{Tg}$ - temperatura de globo, ${ }^{\circ} \mathrm{C}$

Os valores de IBUTG obtidos foram confrontados com aqueles considerados como limites tolerantes, obtidos na Tabela 2 por intermédio da Tabela 1.

Tabela 1. Taxas de metabolismo por tipo de atividade

\begin{tabular}{lc}
\hline \multicolumn{1}{c}{ Tipo de atividade } & Kcal $\mathbf{~}^{-1}$ \\
Sentado em repouso & 100 \\
Trabalho leve & \\
$\begin{array}{l}\text { Sentado, movimentos moderados com braços e tronco } \\
\text { (ex: datilografia) }\end{array}$ & 125 \\
$\begin{array}{l}\text { Sentado, movimentos moderados com braços e pernas } \\
\text { (ex: dirigir) }\end{array}$ & 150 \\
$\begin{array}{l}\text { De pé, trabalho leve, em máquinas ou bancada, principalmente } \\
\text { com braços }\end{array}$ & 150 \\
$\begin{array}{l}\text { Trabalho moderado } \\
\text { Sentado, movimentos vigorosos com braços e pernas }\end{array}$ & 180 \\
$\begin{array}{l}\text { De pé, trabalho leve em máquina o u bancada, com alguma } \\
\text { movimentação }\end{array}$ & 175 \\
$\begin{array}{l}\text { De pé, trabalho moderado em máquina ou bancada, } \\
\text { com alguma movimentação }\end{array}$ & 220 \\
Em movimento, trabalho moderado de levantar ou empurrar & 300 \\
Trabalho pesado & \\
Trabalho intermitente de levantar, empurrar ou arrastar pesos & 440 \\
Trabalho fatigante & 550 \\
\hline
\end{tabular}

Fonte: NR 15 (2004) 
Tabela 2. Limites de tolerância para trabalhos intermitentes com períodos de descanso no próprio local de trabalho, em IBUTG $\left({ }^{\circ} \mathrm{C}\right)$

\begin{tabular}{|c|c|c|c|}
\hline \multirow{2}{*}{$\begin{array}{l}\text { Regime de trabalho intermitente com descanso } \\
\text { no próprio local de trabalho (por hora) }\end{array}$} & \multicolumn{3}{|c|}{ Tipo de atividade } \\
\hline & Leve & Moderada & Pesada \\
\hline Trabalho contínuo & até 30,0 & até 26,7 & até 25,0 \\
\hline $\begin{array}{l}45 \text { min de trabalho } \\
15 \text { min de descanso }\end{array}$ & 30,1 a 30,6 & 26,8 a 28,0 & 25,1 a 25,9 \\
\hline $\begin{array}{l}30 \text { min de trabalho } \\
30 \text { min de descanso }\end{array}$ & 30,7 a 31,4 & 28,1 a 29,4 & 26,0 a 27,9 \\
\hline $\begin{array}{l}15 \text { min de trabalho } \\
45 \text { min de descanso }\end{array}$ & 31,5 a 32,2 & 29,5 a 31,1 & 28,0 a 30,0 \\
\hline Não é permitido o trabalho sem a adoção de medidas adequadas de controle & acima da 32,2 & acima de 31,1 & acima de 30,0 \\
\hline
\end{tabular}

Fonte: NR 15 (2004)

De posse dos dados coletados utilizou-se a estatística descritiva para confrontar os dados de ITGU com médias horárias, em função das semanas estudadas. Os valores de IBUTG foram confrontados com os limites estabelecidos pela Norma Regulamentar (NR) do Ministério do Trabalho e Emprego.

\section{Resultados e Discussão}

De acordo com Menegali et al. (2010) em trabalho realizado com frangos de corte no período do inverno, verificou-se que os animais estão em conforto térmico quando o ITGU analisado está entre 74 e 77, segundo dados confrontados com a literatura. Abaixo de 74 os frangos estão expostos a baixas temperaturas enquanto que nos valores acima de 77, o desempenho das aves fica prejudicado em razão das altas temperaturas. $\mathrm{O}$ comportamento do ITGU durante as três primeiras semanas de vida dos pintos de corte, está ilustrado na Figura 1.

Durante o período de inverno verificou-se que apenas nas primeira e segunda semanas, antes das 10:00 e 09:00 h, respectivamente, os valores de ITGU estiveram abaixo de 74 (Figura 1). Nos demais horários e na terceira semana os valores de ITGU estiveram acima do preconizado, sobretudo no período entre as 12 e $15 \mathrm{~h}$, alcançando valores de até 83 na terceira semana, condição caracterizada perigosa.

Durante a primeira semana o sistema de aquecimento tipo asa de morcego foi utilizado para manter o local com

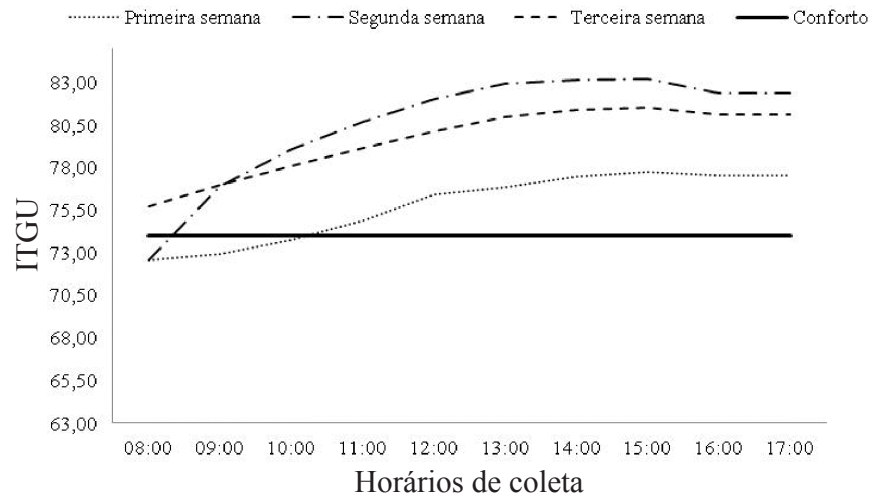

Figura 1. Valores médios (horários) de ITGU coletados durante as três primeiras semanas de vida dos pintos de corte no período de inverno, na região do semiárido mineiro temperatura entre 32 e $34{ }^{\circ} \mathrm{C}$ e com cortinas fechadas, para evitar redução da temperatura ambiente. Na segunda semana o sistema de aquecimento foi suspenso e as cortinas começaram a ser abaixadas até a metade da sua altura total, a partir das 09:00 $\mathrm{h}$ para auxiliar na renovação do ar e às $15 \mathrm{~h}$ eram fechadas novamente. Conforme as aves foram crescendo, a partir do $14^{\circ}$ dia as cortinas eram abaixadas totalmente no período da manhã, a partir das $09 \mathrm{~h}$ e suspensas às $15 \mathrm{~h}$.

De acordo com os valores apresentados na Figura 1, verificou-se que, mesmo com o sistema de aquecimento funcionamento, somente na primeira semana o ambiente esteve com as temperaturas elevadas, apesar da época de inverno. Este resultado leva a crer que não há necessidade de manter o galpão totalmente fechado e que o simples manejo de cortina, sobretudo nos horários de maiores temperaturas associado ao rápido acionamento do ventilador seria interessante para ajudar a reduzir a temperatura interna do galpão.

$\mathrm{O}$ ambiente em que as aves estão inseridas constitui um dos principais responsáveis pelo sucesso ou fracasso do empreendimento avícola, uma vez que os fatores térmicos (radiação térmica, temperatura, umidade e movimentação do ar) comprometem a função vital mais importante dos animais: a homeotermia (Tinôco, 2001). Segundo Menegali et al. (2013) e de acordo com dados comparados aos da literatura, valores acima de 84 representam emergência, necessitando de intervenções como ventilação, nebulização e paisagismo circundante, para auxiliar no conforto térmico dos animais. Valores próximos a 84 , foram verificados nos horários entre as 13 e $15 \mathrm{~h}$.

$\mathrm{Na}$ segunda fase experimental ocorrida durante o verão verificou-se que, a partir das 08:00 h, os animais estavam expostos a valores de ITGU superiores a 74, atingindo a condição de emergência a partir das $11 \mathrm{~h}$, inclusive na primeira semana de vida, como pode ser observado na Figura 2.

Segundo Pelicano et al. (2005) a temperatura ambiente elevada reduz o ganho de peso de frangos de corte, uma vez que aumentam as trocas latentes (evaporação) e o consumo de água. De acordo com Medeiros et al. (2005) com o aumento no consumo de água as fezes ficam líquidas ocasionando elevação na umidade da cama, com consequente redução de seu poder de absorção e aumento na concentração de amônia no ar, que em alguns casos pode atingir níveis críticos.

O calor estimula os neurônios específicos que estão localizados na parte anterior do hipotálamo, onde se encontra 


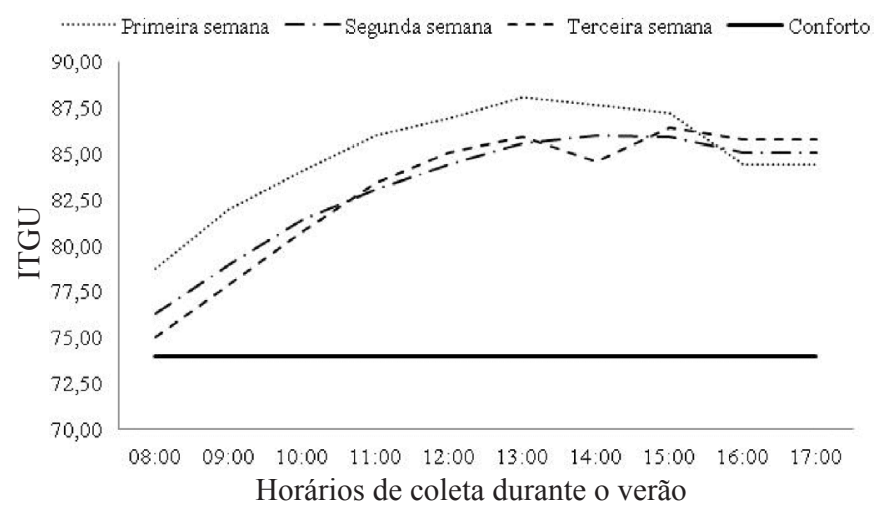

Figura 2. Valores médios horários de índice de temperatura de globo negro e umidade (ITGU) coletados durante as três primeiras semanas de vida dos pintos de corte no período de verão na região do semiárido mineiro

o centro do apetite (Tinôco \& Gates, 2005). De acordo com os autores, valores de ITGU acima de 75 são limitadores do desenvolvimento produtivo e reprodutivo dos frangos de corte.

Para Medeiros et al. (2005) em condições de calor as aves ficam agitadas e se dispersam para aumentar a dissipação corporal para o ambiente. Com o passar do tempo, param de movimentar-se, ficam bastante ofegantes, prostradas e têm a frequência cardíaca cada vez mais aumentada.

Neste caso, o uso de equipamentos de ventilação associado ao manejo de cortinas de forma constantes, é um interessante recurso de alívio ao estresse térmico (Nääs et al., 2005).

$\mathrm{Na}$ Figura 3 estão apresentados os valores das médias horárias do IBUTG durante a jornada de trabalho e as três primeiras semanas de vida dos pintos de corte, no período de inverno.

De acordo com a Tabela 1, as atividades de manejo em um galpão de frangos de corte são consideradas pesadas (NR 15, 2004) o que remete ao entendimento de exposição do tratador a condições de sobrecarga térmica para uma jornada de $8 \mathrm{~h}$ de trabalho. $\mathrm{O}$ trabalho de manejo desse galpão é realizado por duas pessoas e consiste no abastecimento manual dos comedouros, limpeza dos bebedouros, revolvimento manual da cama com o auxílio de enxada e retirada dos animais mortos.

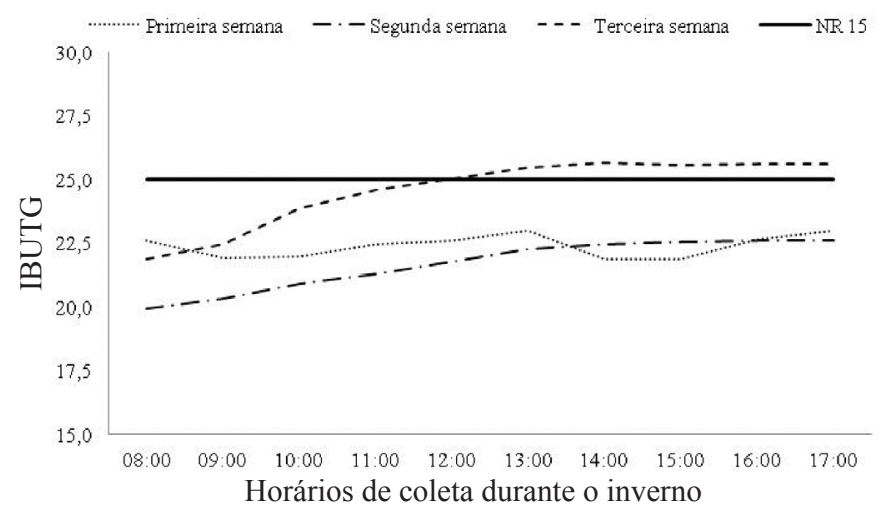

Figura 3. Valores de índice de bulbo úmido e termômetro de globo negro (IBUTG) em função das semanas estudadas e relação com a classificação da atividade, durante o período de inverno no semiárido mineiro
Verifica-se, porém, por meio da Figura 3, que os trabalhadores estão expostos a condição de sobrecarga térmica somente a partir das $12 \mathrm{~h}$ na terceira semana de vida dos pintos de corte, fato que reflete a necessidade da adoção de pausas somente de acordo com a carência dos trabalhadores devido ao fato do trabalho ser classificado como pesado, e não com a adoção de pausas programadas, como é exigido pela NR 15, uma vez que a condição térmica não é, neste caso, um fator que expõe os trabalhadores a estresse.

Carvalho et al. (2012) verificaram, avaliando a condição de trabalho em galpões para frangos de corte durante a fase de pinteiro no inverno, condição de sobrecarga térmica e física no período em torno de 9 até as $18 \mathrm{~h}$, com destaque para o período crítico entre as 11 até $15 \mathrm{~h}$, sendo recomendada a adoção de pausas para descanso.

O paisagismo circundante era presente ao redor do galpão avaliado, condição esta que, associada à época do ano, proporcionou valores de IBUTG abaixo do limite máximo, o que torna a atividade de manejo menos estressante para o trabalhador.

Para Tinôco (2001) a possibilidade de existência de árvores na face leste ou oeste de construções abertas é bastante desejável (como divisórias de alto amortecimento) para evitar a incidência da irradiância solar direta dentro das áreas das coberturas. A vegetação em geral, seja promovendo sombra natural sobre as coberturas, seja criando regiões com microclima ameno, pode reverter completamente uma situação de desconforto térmico.

Buscando avaliar a contribuição do sombreamento arbóreo para amenizar a radiação solar em instalações avícolas em duas diferentes orientações, leste-oeste e norte-sul, Alves \& Rodrigues (2004) observaram que tanto para instalações com orientação leste-oeste quanto para orientação norte-sul, o uso do paisagismo circundante foi muito relevante mas durante a época de verão, quando realizada a repetição do trabalho de caracterização do ambiente térmico para animais e humanos, verificou-se que o paisagismo circundante não auxiliou na redução do IBUTG no interior do galpão, como pode ser observado na Figura 4, uma vez que os valores de IBUTG foram superiores ao recomendado pela NR 15 para trabalho contínuo, durante as três semanas experimentais.

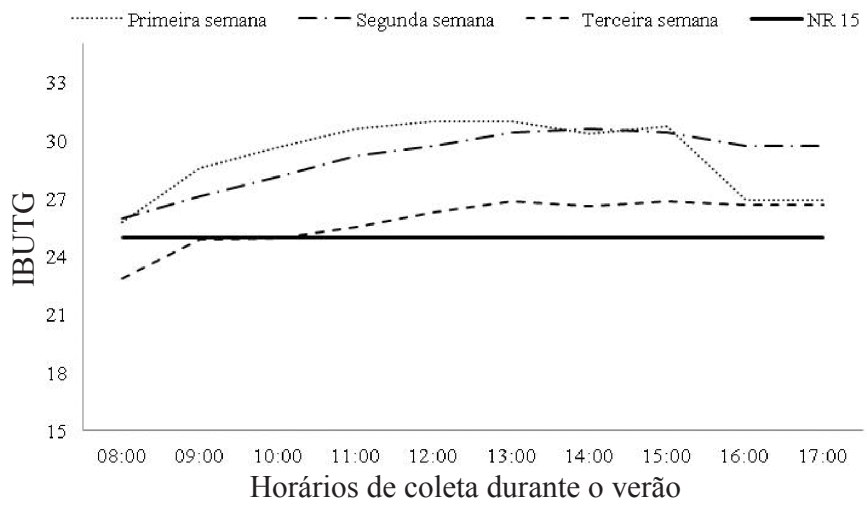

Figura 4. Valores de índice de bulbo úmido e termômetro de globo negro (IBUTG) em função das semanas estudadas e relação com a classificação da atividade, durante o período de verão no semiárido mineiro 
Diante dos dados ilustrados na Figura 4, entende-se que é necessário que o trabalhador realize a adoção de pausas programadas pelo menos a cada 30 min para sua recuperação fisiológica, visto que a condição térmica é fator determinante nessa época do ano.

De acordo com Carvalho et al. (2011) a execução de trabalhos considerados pesados em condição de clima quente, merece atenção especial quanto aos fatores ergonômicos, ambiente de trabalho, alimentação e as pausas haja vista estarem sujeitos ao maior desgaste físico durante o trabalho.

Os problemas de saúde mais comuns em aviários estão relacionados a dores músculo-esqueléticas na região lombar devido às atividades manuais de limpeza de bebedouros e comedouros (Alencar et al., 2006; Evangelista et al., 2012).

Segundo Grandjean (1998) o calor excessivo em ambientes de trabalho resulta em cansaço e sonolência, que reduzem a prontidão de resposta e aumentam a tendência a falhas.

O uso de sistema de ventilação, nebulização e pausas programadas são medidas que podem ser adotadas a fim de minimizar a condição de estresse térmico evidenciada no interior do galpão que comprometem a eficiência do trabalho realizado pelos funcionários e sua saúde.

\section{Conclusões}

1. Tanto no inverno como no verão na região do semiárido mineiro, os animais estão expostos a condições de estresse térmico por calor.

2. A época de inverno é a mais adequada para a realização das atividades de manejo; entretanto, no verão a condição climática é um fator que prejudica a eficiência do trabalho realizado pelos trabalhadores.

\section{Agradecimentos}

À Fundação de Amparo à Pesquisa do Estado de Minas Gerais (FAPEMIG) e à Universidade Estadual de Montes Claros (UNIMONTES).

\section{Literatura Citada}

Alencar, M. C. B.; Nääs, I. A.; Salgado, D. D’A.; Gontijo, L. A. Mortalidade de frangos de corte e comportamento humano no trabalho. Scientia Agrícola, v.63, p.529-533, 2006.

Alves, S. P.; Rodrigues, E. H. V. Sombreamento arbóreo e orientação de instalações avícolas. 2004. Revista Engenharia Agrícola, v.24, p.241-245, 2004.

Buffington, D. E.; Collazo-Arocho, A.; Canton, G. H. Pitt, D. Black globe humidity index (BGHI) as a comfort equation for dairy cows. Trans. ASAE, v.24, p.711-714, 1981.

Carvalho, C. C. S.; Souza, C. F.; Tinôco, I. de F. F.; Vieira, M. F. A.; Menegali, I.; Santos, C. R. Condições ergonômicas dos trabalhadores em galpões de frangos de corte durante a fase de aquecimento. Revista Brasileira de Engenharia Agrícola e Ambiental, v.16, p.1243-1251, 2012.
Carvalho, C. C. S.; Souza, C. F.; Tinôco, I. de F. F.; Vieira, M. F. A.; Minette, L. J. Segurança, saúde e ergonomia de trabalhadores em galpões de frangos de corte equipados com diferentes sistemas de abastecimento de ração. Revista Engenharia Agrícola, v.31, p.438-447, 2011.

Cordeiro, M. B.; Tinôco, I. de F. F.; Mesquita Filho, R. M. de; Sousa, F. C. Análise de imagens digitais para a avaliação do comportamento de pintainhos de corte. Engenharia Agrícola, v.31, p.418-426, 2011.

Damasceno, F. A.; Yanagi Júnior, T.; Lima, R. R.; Gomes, R. C. C.; Moraes, S. R. P. Avaliação do bem-estar de frangos de corte em dois galpões comerciais climatizados. Ciência e Agrotecnologia, v.34, p.1031-1038, 2010.

Evangelista, W. L.; Tinoco, I. de F. F.; Souza, A. P.; Minetti, L. J.; Baêta, F. C.; Silva, E. P.; Oliveira, L. A. Postural analysis of workers in a typical meat processing company in Brazil. Work: A Journal of Prevention, Assessment and Rehabilitation, v.41, p.5392-5394, 2012.

Grandjean, E. Manual de ergonomia: Adaptando o trabalho do homem. Porto Alegre: Bookman, 1998. 94p.

Medeiros, C. M.; Baêta, F. C.; Oliveira, R. F. M.; Tinôco, I. de F. F.; Albino, L. F. T.; Cecon, P. R. Efeitos da temperatura, umidade relativa e velocidade do ar em frangos de corte. Revista Engenharia na Agricultura, v.13, p.277-286, 2005.

Menegali, I.; Baeta, F. C.; Tinoco, I. de F. F. ; Cordeiro, M. B. ; Guimarães, M. C. C. Desempenho produtivo de frangos de corte em diferentes sistemas de instalações semiclimatizadas no sul do Brasil. Engenharia na Agricultura, v.18, p.461471, 2010.

Menegali, I.; Tinoco, I. de F. F.; Carvalho, C. C. C.; Souza, C. F.; Martins, J. H. Comportamento de variáveis climáticas em sistemas de ventilação mínima para produção de pintos de corte. Revista Brasileira de Engenharia Agrícola e Ambiental, v.17, p.106-113, 2013.

Nääs, I. A.; Pereira, D. F.; Baracho, M. S. Bem estar e comportamento. Manejo de matrizes de corte - Campinas: FACTA, 2005. p.45-52. 421p.

NR 15 - Atividades e operações insalubres. In: Segurança e medicina do trabalho. São Paulo: Atlas, 2004.

Pelicano, E. R. L.; Bernal, F. E. M.; Furlan, R. L. Efeito da temperatura ambiente e da restrição alimentar proteica ou energética sobre o ganho de peso e crescimento ósseo de frangos de corte. Arquivo Brasileiro de Medicina Veterinária e Zootecnia, v.57, p.353-360, 2005.

Ponciano, P. F.; Lopes, M. A.; Yanagi Júnior, T.; Ferraz, G. A. S. Análise do ambiente para frangos por meio da lógica Fuzzy: uma revisão. Archivos Zootecnia, v.60, p.1-13. 2011.

Tinôco, I. de F. F. Avicultura industrial: Novos conceitos de materiais, concepções e técnicas construtivas disponíveis para galpões avícolas brasileiros. Revista Brasileira de Ciência Avícola, v.3, p.1-26, 2001.

Tinôco, I. de F. F.; Gates, R. S. Manejo de matrizes de corte. Editado por Marcos Macari e Ariel Antônio Mendes Campinas: FACTA, 421p. p.18-19, 2005. 